\section{Demand for healthcare in India}

\author{
Brijesh C. Purohit \\ Madras School of Economics, Kottur, \\ India
}

\section{Abstract}

In a developing country like India, allocation of scarce fiscal resources has to be based on a clear understanding of how investments in the heath sector are going to affect demand. Three aspects like overall healthcare demand, consumer decisions to use public and/or private care and role of price/quality influencing poor/rich consumer's decisions are critical to assessing the equity implications of alternative policies. Our paper addresses these aspects through examining the pattern of healthcare demand in India. Data from the National Family Health Survey are used to model the healthcare choices that individuals make. We consider what these behavioral characteristics imply for public policy. This analysis aims to study disparities between rural and urban areas from all throughout India to five Indian states representing three levels of per capita incomes (all-India average, rich and poor). Results evidence that healthcare demand both in rural and urban areas is a commodity emerging as an essential need. Choices between public or private provider are guided by income and quality variables mainly with regard to public healthcare denoting thus a situation of very limited alternatives in terms of availing private providers. These results emphasize that existing public healthcare facilities do not serve the objective of providing care to the poor in a satisfactory manner in rural areas. Thus, any financing strategy to improve health system and reduce disparities across rich-poor states and rural-urban areas should also take into account not only overcoming inadequacy but also inefficiency in allocation and utilization of healthcare inputs.

\section{Introduction}

Public spending on healthcare has been one of the few uncontroversial issues of welfare.

In the last decade, Indian government has been under a dual internal and external pressure to reduce overall spending and simultaneously maintain adequate and efficient health services. To achieve the goals of health for all laid out by National Health Policy, ${ }^{1}$ the focus on primary care or marginally increasing public sector had to be re-assessed.

However, it is less than obvious whether governments spend money in an appropriate fashion to raise access to healthcare services. In a developing country like India, allocation of scarce fiscal resources has to be based on a clear understanding of i) how investments in the heath sector affect demand; ii) how changes in the pricing of public services and investments in quality improvements affect consumer decisions; and iii) how poor $v s$ nonpoor consumers make decisions about treatment relative to both pricing and quality.

These three aspects - overall healthcare demand, consumer decisions to use public and/or private care and role of price/quality influencing poor/rich consumers' decisions are critical to assessing the equity implications of alternative policies. Our paper addresses these aspects through examining the pattern of healthcare demand in India. We use data from the National Family Health Survey (NFHS 3) to model the healthcare choices that individuals make when sick or injured. We then consider what these behavioral characteristics imply for public policy. First, we are interested in how changes in the availability of services will affect their use. A second important contribution of this paper is that it examines the impact of the quality of medical care on health demand. The call for improving quality is advocated by policy makers, action researches and international organizations. Nonetheless, studies on the effect of quality when choosing a provider are scarce. Besides, we also examine how a series of other characteristics of the household, and individuals, affect their healthcare choices. The role of education, age, etc. provides important insights into the potential opportunities and limitations of public policy to affect patterns of demand.

This analysis aims to study disparities between rural and urban areas from all throughout India to five Indian states representing three levels of per capita incomes (allIndia average, rich and poor). The model used assumes that people have a limited number of healthcare options available, which is entirely plausible both for rural and urban areas by distinguishing each type of provider into public or private.

\section{Materials and Methods}

In the literature, basic approach to the demand for health ${ }^{2}$ is labeled as the human capital model because it draws heavily on human capital theory. ${ }^{3-6}$ This framework was used $^{4,5}$ to develop models determining the optimal quantity of investment in human capital at any age. In addition, these models show how the optimal quantity varies over the life cycle of an individual and among individuals of the
Correspondence: Brijesh C. Purohit,

Madras School of Economics, Gandhi Mandapam Road, Kottur, Chennai-600025, India.

Tel. +91.044.2230.0304 - Fax: +91.044.2235.4847.

E-mail: brijeshpurohit@gmail.com

Key words: healthcare, health policy, inequity, Indian states.

Received for publication: 14 December 2012

Accepted for publication: 2 February 2013.

This work is licensed under a Creative Commons Attribution 3.0 License (by-nc 3.0).

(C) Copyright B.C. Purohit., 2013

Licensee PAGEPress, Italy

Healthcare in Low-resource Settings 2013; 1:e7 doi:10.4081/hls.2013.e7

same age. According to human capital theory, increases in a person's stock of knowledge or human capital raise his productivity in the market sector of the economy, where he produces money earnings, and in the non-market or household sector, where he produces commodities that enter his utility function. To realize potential gains in productivity, individuals have an incentive to invest in formal schooling and on-the-job training. The costs of these investments include direct outlays on market goods and the opportunity cost of the time that must be withdrawn from competing uses. Grossman approach uses the household production function model of consumer behavior ${ }^{7}$ ${ }^{9}$ to account for the gap between health as an output and medical care as one of many inputs into its production. This model has also been further elaborated ${ }^{10-13}$ and, somewhat differently, also resembles proximate determinants model of health. ${ }^{14}$ This model draws a sharp distinction between fundamental objects of choice (commodities) that enter the utility function and market goods and services. Consumers produce commodities with inputs of market goods and services and their own time. For example, they use sporting equipment and their own time to produce recreation, likewise they use medical care, nutrition, etc. to produce health. The concept of a household production function is perfectly analogous to a firm production function. Each relates specific outputs to a set of inputs. Since goods and services are inputs into the production of commodities, the demand for medical care and other health inputs is derived from the basic demand for health.

There is an important link between the household production theory of consumer behavior and the theory of investment in human capital. Consumers as investors in their human capital produce these investments with inputs of their own time. Thus, some of the outputs of household production 
directly enter the utility function, while other outputs determine earnings or wealth in a life cycle context. Health, on the other hand, serves both the functions.

According to the human capital model, ${ }^{2}$ consumers both demand and produce health. Health is a choice variable because it is a source of utility (satisfaction) and determines income or wealth levels. Health is demanded by consumers for two reasons: i) as a consumption commodity, it directly enters their preference functions; ii) as an investment commodity, it determines the total amount of time available for market and non-market activities. An increase in the stock of health reduces the amount of time lost from these activities, and the monetary value of this reduction is an index of the return to an investment in health.

Since health capital is a component of human capital, a person inherits an initial stock of health that depreciates with age, can be increased by investment, and falls below a certain level with death. The model originally proposes that individuals choose their length of life. Gross investments are produced by household production functions that relate an output of health to such choice variables (or health inputs) as medical care utilization, diet, exercise, smoking, and alcohol consumption. In addition, the production function is affected by the efficiency or productivity of a given consumer as reflected by their personal characteristics. Efficiency is defined as the amount of health obtained from a given amount of health inputs. As a fundamental law in economics is the law of the downward-sloping demand function, the quantity of health demanded should be negatively correlated with its shadow price. The shadow price of health is said to depend on many variables other than medical care price. Shifts in these variables alter the optimal amount of health and the derived demand for gross investment and health inputs. The shadow price of health rises with age if the rate of depreciation on the stock of health rises over the life cycle and falls with education if more educated people are more efficient producers of health. The model stresses that, under certain conditions, an increase in the shadow price may simultaneously reduce the quantity of health demanded and increase the quantities of health inputs demanded. To develop empirically testable hypotheses, a model of the demand for health defined in terms of different indicators of mortality and diseases is specified. The model concentrates on the role of money and time prices, earned and non-earned income and health insurance. A number of socio-economic variables including religion, caste, education, assets are also used in empirical estimation. To simplify, the formal model is developed in terms of one provider of health only, but the implications for

several providers can easily be drawn.

If the inter-temporal utility function of a typical consumer is

$\mathrm{U}=\mathrm{U}(\Delta \mathrm{tHt}, \mathrm{Zt}), \mathrm{t}=0,1, \ldots, \mathrm{n}$

where: Ht is the stock of health at age/time period $\mathrm{t}, \Delta \mathrm{t}$ is the service flow per unit stock, $\mathrm{ht}=\Delta \mathrm{tHt}$ is total consumption of health servic$e s$, and $\mathrm{Zt}$ is consumption of another commodity.The stock of health in the initial period $\left(\mathrm{H}_{0}\right)$ is given, but the stock of health at any other age is endogenous. Life length as of the planning date (n) also is endogenous. In particular, death takes place when $\mathrm{Ht} \Delta \mathrm{H}_{\text {min }}$. Therefore, life length is determined by the quantities of health capital maximizing utility subject to production and resource constraints. If we write $\mathrm{ht}=\Delta \mathrm{tH} t=\mathrm{m}$ denoting medical services or any other commodity or characteristic leading to health, assume that two goods enter the individual's utility function (medical services $\mathrm{m}$, and a composite X) for all other goods and services, also presume a fixed proportions of money and time to consume $\mathrm{m}$ and $\mathrm{X}$, and combine these with the full wealth assumption, the model can be represented as follows. ${ }^{15}$

Maximize: $\mathrm{U}=\mathrm{U}(\mathrm{m}, \mathrm{X})-$ Subject to $(\mathrm{p}+\mathrm{wt}) \mathrm{m}$ $+(q+w s) X \leq y+w T=Y$

where: $\mathrm{U}=\mathrm{utility} ; \mathrm{m}=$ medical services; $\mathrm{X}=$ all other goods and services; $\mathrm{p}=$ out-of-pocket money price per unit of medical services; $t=0 w n$-time input per unit of medical services consumed; $q=$ money price per unit of $\mathrm{X}$; $s=0 w n$-time input per unit of $X ; w=e a r n i n g s$ per hour; $Y=$ total income; $y=$ non-earned income; $\mathrm{T}$ =total amount of time available for market and own production of goods and services. Here the consumption of $m$ does not affect the amount of T. Based on the optimization process, the reduced-form demand functions for medical care (Mt) can be derived as:

$\mathrm{Mt}=\mathrm{M}(\mathrm{p}, \mathrm{q}, \mathrm{w}, \mathrm{V}, \mathrm{H}, \mathrm{E}$; et $)$

where: $\mathrm{E}$ is a vector of individual, family and community characteristics, $\mathrm{V}$ is the current annual household wealth income, and et is the unobserved initial endowment.

Most empirical studies use the reduced form approach and include both sets of variables denoting either demand and/or production function variables to analyze the determinants of healthcare. The conditional demand for curative care can be specified as:

$\left[M_{i} \mid H_{i}=1\right]=b_{1}+b_{2} P_{i}+b_{3} V_{i}+b_{4} E i+e_{i}, i=1,2 \ldots m$ sick persons

where: $\mathrm{E}$ is a vector of individual, household and community variables and $\mathrm{M}$ is the choice of health-care provider taking discrete values.
$\mathrm{M}=0$, if taking no treatment, or taking self treatment and other care (other than public and private) facilities; $M=1$, if public health facilities are used for treatment; $M=2$, if private healthcare is utilized.

Using the above basic consumption model formulation, and a reduced form equation, the effect of various parameters on health could be tested in a regression framework. Literature from the health economics field mainly indicate five sets of factors that could be considered important to explore. ${ }^{16}$ These include socioeconomic status, access to health services, environment, nutrition and personal attributes, etc. ${ }^{17}$ The conditional demand for curative care (Equation 4) is a discrete choice model involving three choices and hence estimated using appropriate logit method.

Generally, rural and urban populations tend to differ with respect to many health indicators. Urban population is typically presumed to be better off. Reality is depicted more vividly when a disaggregate scenario is analyzed using an acceptable measure of income categories. Empirically, in some countries like Colombia and Peru, indicators suggest that the urban poor are worse off than their rural counterparts, and the health status of the urban population varies widely across countries, provinces and city sizes. ${ }^{18,19}$

In addition, urban populations are more susceptible due to degradation of physical environment. For instance, a study on São Paolo, Brazil, finds that an increase in airborne contamination (which is higher in cities) results in increased hospitalization due to respiratory illness and pneumonia. ${ }^{20}$ Thus, that higher income is positively correlated with better health is another set of presumption, with the direction of causality clearly established from wealthier to healthier, ${ }^{21}$ urban poor can experience problems with their physical environment that are distinct from and have greater negative health impacts than those faced by their rural counterparts. Moreover, personal hygiene, nutrition, choice of physical activities and employment can have an extremely important effect on health in terms of incidence of obesity, heart disease, cancer, sexually-transmitted diseases and similar kind of chronic lifestyle diseases. A notable trend across the globe is a steady increase in urban populace with nearly $1 / 3$ of urban dwellers in slums. It is estimated that nearly $30 \%$ (about 300 million) Indian people live in towns and cities and nearly 100 million of them live in slums characterized by overcrowding, poor hygiene, and absence of proper civic services..$^{22}$ To conclude, we can reasonably presume that urban poor's health is as worse as the rural population's.

By systematic planning since independence, health system in India focuses more on rural areas having an organizational structure from the basic to tertiary care managed by dedicat- 
ed staff. ${ }^{23}$ In contrast, such healthcare structure is highly deficient in urban areas. Majority of healthcare in urban areas is served by the private sector, but its costing, distance and many other factors make it out of reach for most urban poor residents. In the last 45 years healthcare system in India has focused on increasing coverage in rural areas. Urban health problems have been assumed to be fewer since health facilities and services highly concentrate in cities compared with rural areas. In fact, urban poors' level of access to health facilities falls below the minimum equitable level, where primary healthcare facilities, their location, resources, quality and performance are often poor, their links to deprived communities inadequate and their utilization low. ${ }^{24}$ Thus, a wide gap in the utilization pattern of health services and health improvement in urban areas exists. ${ }^{25}$

A priori, based on the formal model of demand for health services, time is expected to function as a normal price, demand for free care to be more sensitive to changes in time prices than demand for non-free care. The elasticity of demand for medical services with respect to non-earned income should be positive and the elasticity of demand with respect to earned income is indeterminate, but the price effect may dominate for free care (and thus reduce demand) and the income effect may dominate for non-free care (and thus increase demand). Furthermore, without differences in taste for particular types of providers, more education may reduce care demand. If there are taste differentials (with the more educated preferring private care), there may be a negative elasticity with respect to education for public care and an elasticity biased upward (possibly positive) for private care.

\section{Data source}

In order to carry out regression exercise we have made use of the third National Family Health Survey (NFHS-3). ${ }^{26}$ NFHS-3 was conducted in 2005-2006 and provides information on fertility, mortality, family planning, HIVrelated knowledge, and important aspects of nutrition, health, and healthcare. Unlike earlier surveys, NFHS-3 interviewed men aged 1554 , never married women aged 15-49, evermarried women, and included questions on several emerging issues. NFHS-3 collected information from a nationally representative sample of 109,041 households, 124,385 women, and 74,369 men. NFHS-3 sample covers $99 \%$ of Indian population living in all 29 states.

Fieldwork for NFHS-3 was conducted in two phases from November 2005 to August

2006. A total of 515,507 individuals who stayed in the household the night before the interview were enumerated in the 109,041
NFHS-3 sample households. The age distribution of the population is typical of populations that have recently experienced fertility decline. Under age 15 is $35 \%$ of the population, and only $5 \%$ is 65 and older. Women represent the $14 \%$ of heads of households. Over $2 / 3$ $(69 \%)$ of the population lives in rural areas. Based on the religion of the household head, $82 \%$ of households is hindu, $13 \%$ muslim, $3 \%$ christian, $2 \%$ sikh and 1\% buddhist/neo-buddhist. All other religions together account for $<1 \%$ of households. Nineteen percent of household heads belong to the scheduled castes, $8 \%$ to the scheduled tribes, and $40 \%$ to the other backward classes (OBC). About 1/3 do not belong to any of these three groups. Twenty-seven percent of households have a below poverty line (BPL) card.

A separate analysis at the state level was also done using the same data source. We included five states: Gujarat, Maharashtra (both rich states), Karnataka (an average income state), and Madhya Pradesh (MP) and Rajasthan (both poorer states). These states are considered poor, middle income and rich depending upon their per capita state income being much below, nearer or much above allIndia average per capita income. The dependent variables used are: i) respondent used any source of public healthcare (PUBCARE), ii) respondent used any private healthcare (PVTCARE), and iii) respondent used any source of healthcare (ANYCARE). Among the explanatory variables we used reasons for not using a public or private source of care, namely, nonearby facility (NONFACTY), facility timing not convenient (TIMENC), health personnel often absent (HPABST), waiting time too long (WAITTL) and poor quality of care as perceived by the respondents (PQUAC). These five variables are presumed to denote quality aspect of care. Among socio-economic variables we used wealth index (WI), BPL card holding (BPL), female education (FEEDU), highest education level in the household (HEDULH), religion (RELGN), caste (CASTE), insurance coverage from any source (INSANY), source of water supply (WATSS), type of sanitation (SANTYP) and having electricity (ELECTR).

\section{Results and Discussion}

\section{All-India analysis: rural vs urban}

Below we discuss results of our logit analysis which are presented in the Appendix (Tables As listed below). Results of the rural all-India level indicate that all the variables are significant. Among the explanatory variables, quality as represented by different variables indicates that utilization of governmental facilities is hampered by distance, inconvenient timing of facility, absence of health per- sonnel, and poor perceived quality of care.

The marginal impact of these variables is however small (Table A1). The responsiveness (elasticity of) of these variables is particularly high in determining the utilization of governmental facilities. Among the socio-economic variables, BPL card holding has a positive impact, but both the marginal effect and elasticity are low. Likewise, asset ownership (as depicted by composite wealth index) has a negative impact with low elasticity. As expected, rural results indicate female education as leading to more utilization. However, the rural results depict a negative impact of SC/ST belonging and sanitation facilities. Other variables like religion and electricity have positive impact on public health facility utilization. In contrast to governmental facility utilization, private healthcare facility utilization has positive but low elasticity with respect to quality variables in rural areas (Table A2). Poverty hampers the utilization of private providers in the rural results. This is denoted by negative impact of BPL card holding. It is pertinent to note that income elasticity as denoted by wealth index has been low in rural areas relating to any type of care utilization (Table A3). Likewise, elasticity with respect to quality variables has been high only in the results of governmental facility but low in private or any type of care (Tables A2 and A3). Education elasticity has been low but negative in private or any type of care. Low level of water sanitation facilities have a positive impact on any type of care, but elasticity coefficients are also low. Most importantly, these results prove healthcare as necessity with low elasticities with respect to income and other socio-economic variables. Nevertheless, the choice of a better provider (governmental $v s$ private or no facility $v s$ any facility) is seen through high responsiveness of rural respondents. A major difference between rural and urban results (Tables A4A6) is in terms of impact of BPL status. In urban areas, BPL status has been a negative factor in the utilization of any type of healthcare facility. However, another factor, namely SC/ST status, unlike rural areas, has a positive impact albeit with low magnitude. In the urban results, female education has been negatively influential in the utilization of private or any type of facilities but it did not emerge as significant for public facilities. There is no notable difference between rural-urban results in terms of water-sanitation impact which shows mixed results. In general, for all the three types of dependent variables, magnitude of income elasticity has been higher in urban areas relative to the rural counterparts, but the difference in magnitude is also low. In the case of individual state level results, among rich states, the results for Gujarat indicate that for public healthcare facilities in rural areas variables representing BPL status, insurance, reli- 
gion, education and water source have not emerged as statistically significant (Table A7). These variables have even demonstrated to be insignificant for private facilities or any type of care (Tables A8 and A9). Pertinently, the results for rural Gujarat indicate high negative elasticity with respect to quality variables impinging on utilization of public healthcare facilities. However, income elasticity for either facility has been low for rural areas (Tables A8 and A9). An interesting observation is the high income elasticity as well as quality elasticity for public healthcare utilization in urban Gujarat (Table A10). By contrast, in this set of results, variables representing BPL status, insurance coverage, and amenities variables like sanitation and electricity have not emerged as significant. Nor is the female education is found significant. Thus it indicates that respondents in Urban Gujarat had most important criteria as income and quality to utilize public healthcare (Table A10). However, the elasticity is much lower in magnitude for either private or any type of care in urban Gujarat both with respect to quality and income. (Tables A11 and A12)

Results for Maharashtra indicate that some of the socio-economic variables like insurance, SC/ST belonging, wealth index and religion have not emerged as significant for the rural results pertaining to public healthcare utilization (Table A13). Even among the quality variables only two of them, namely no nearby facility and poor quality, have emerged with high elasticity (Table A13). However, elasticity coefficients have been low for all other results in rural Maharashtra (Tables A14 and A15). In line with public healthcare utilization, the results of private care and any type of care also denote some of the socio-economic variables like BPL, wealth index, female education, water and sanitation (in private care rural Maharashtra; Table A14) and SC/ST belonging, female education, religion and sanitation (in any type of care rural Maharashtra; Table A15) are not significant.

In line with other rich state, namely Gujarat, the results of urban Maharashtra also indicate high elasticity coefficients both with respect to quality and income variable in deciding utilization of public health facilities (Table A16). In a similar manner, the results of private care utilization and any type of care do not depict high elasticity coefficients (Tables A17 and A18). Again, some of the socio-economic variables like BPL status, wealth index, religion and electricity (in public care utilization urban Maharashtra; Table A16), BPL status and electricity (in private care utilization in urban Maharashtra; Table A17) and SC/ST status, sanitation, wealth index and electricity (in any type of care urban Maharashtra; Table A18) have not emerged as statistically significant.

In line with the all-India rural results, the rural results for Karnataka state (an average income state) also depict high elasticity with respect to quality and income variables only for public healthcare utilization (Table A19). For other types, namely private care and any type of care, elasticity coefficients are low (Table A19). Some of the variables like religion, SC/ST belonging, female education and water facility have not emerged statistically significant for rural results pertaining to public healthcare. Likewise, for private care in rural Karnataka, variables representing BPL status, sanitation type, religion, female education and electricity have not emerged as significant (Table A20). In any type of care religion variable is found insignificant (Table A21). Even the results of urban Karanataka also depict high elasticity coefficients with respect to quality and income variables in the results of public care utilization (Table A22). However, the results for private care utilization in urban Karanataka depict insignificance of religion, SC/ST belonging, electricity, sanitation and wealth index (Table A23). It seems that major determinant for private care utilization even among quality variables is availability, low waiting time and quality since other two quality variables namely vicinity of facility and timing are also insignificant (Table A23). In urban Karnataka the results for any type of care also depict insignificance of SC/ST belonging, religion, female education and sanitation (Table A24).

Results for rural MP depict overall significance of only few variables particularly in regard to utilization of public health facilities. The variables which emerged statistically significant include insurance coverage, type of sanitation and electricity. The impact of these variables and elasticities is low and generally depicts a lack of insurance coverage (negative sign), sanitation (positive sign) and electricity (positive sign) (Table A25). The results of rural MP for private care utilization depict statistically significant coefficients for most of the variables except water and sanitation (Table A26). However, elasticity coefficients are very low for all of them (Table A26), thus again depicting healthcare as a necessity. In case of any type of care, some of the quality variables (timing and absence of personnel) are insignificant (Table A27). However, other quality variables are significant and denote marginal impact as positive only for vicinity of facility and waiting time (Table A27). Likewise, other statistically significant variables include caste (positive sign), source of drinking water (positive sign), income (positive sign of wealth index) and presence of electricity (positive sign). However, both the marginal impact coefficients and elasticities are having low magnitudes (Table A27).

In contrast to rural results, urban MP results depict high impact and elasticities for most of the quality variables except absence of health personnel (Table A28). However, high elasticity is indicated for public health facility (-3.35), inconvenient location of facility (-1.14), long waiting time (-2.42) and poor quality of care (3.72) (Table A28). These depict that urban respondents had preference for private care due to lack of above quality factors at the government facilities. The results also indicate BPL card users with positive low elasticity for public healthcare facilities (.106), negative wealth index coefficient $(-.748)$, religion $(-.322)$ and female education (-.250) (Table A28).

In case of private care utilization, urban MP respondents did not depict high elasticity coefficients for any of the variables. However, the results indicated positive impact of all the quality variables, negative female education effect (elasticity as -.093) and positive elasticity for having electricity (.043) and source of drinking water (.012) (Table A29). These results depict increasing likelihood of private care utilization due to better quality and inadequacy of water sanitation facilities leading to more private care utilization. In line with public care utilization, the results for urban MP depict low impact and elasticity coefficients for all the variables in utilization of any type of care, thus reinforcing the compulsive nature of healthcare (Table A30).

The rural results for another poor state, namely Rajasthan, denote insignificance for public care utilization of all the quality variables (Table A31). Among other variables, only caste and religion have appeared with statistical significance. However, for private care utilization, most of the included variables depict significance (Table A32). Except for insurance coverage, SC/ST belonging and electricity, others have emerged as significant but with low marginal impacts and low elasticity coefficients (Table A32). In case of any type of care, in line with public facilities, many variables depicting, namely, quality, insurance coverage and source of drinking water are statistically insignificant (Table A33). The variables like female education and income have the expected negative sign but low elasticity coefficients (Table A33).

Unlike the results of urban MP, the results for public care utilization for urban Rajasthan do not indicate high elasticity coefficients pertaining to any variables except for poor quality (-1.18) and wealth index (1.49) (Table A34). However, other results for urban Rajasthan do not depict high elasticity coefficients either for private care or any type of care utilization (Tables A35 and A36). Quality variables however have positive and low elasticity for private care (Table A35). Both the income and education variables have the expected negative elasticity (though low in magnitude) for private care utilization in Rajasthan (Table A35). The 
results for any type of care depict mix of low impact and elasticity coefficients (Table A36).

A comparative view of elasticities is provided in Tables A37-A39. Both in rural and urban areas, respondents are responsive to quality variables pertaining to public care utilization. However, except for waiting time, the rural elasticities are higher for quality variables. In terms of income and education, the elasticity coefficients of urban areas are higher than their rural counterparts. A further analysis in terms of rural poor states and rural rich states indicate that the quality variables are not statistically significant (Table A37). These coefficients are very small for poor states and rural areas. In rich states all quality variables in rural areas are significant for Gujarat only. In terms of coefficient's magnitudes, except for poor quality of care, the elasticity coefficients are higher for Gujarat (Table A37). In urban areas, a comparison of two poorer states depicts higher elasticity coefficients for MP for all the quality variables but for income Rajasthan's coefficients are higher and for female education MP's elasticity coefficients are higher. In rich states, comparison of urban areas depict two quality variables namely facility timings and absence of health personnel as statistically insignificant for Maharashtra (Table A37).

Overall, there is a mixed nature of magnitudes between rich states (Gujarat and Maharashtra) pertaining to quality variables in urban areas. Likewise, Maharashtra has higher elasticity for income variables and Gujarat has higher elasticity for female education (Table A37).

In contrast to public care utilization, the elasticity coefficients are generally low across all the categories (Table A38). In general, urban areas have higher elasticities (with low magnitudes) both for quality and income-education variables (Table A38). However, a comparative profile of two poor states in rural areas depicts magnitudes to be uniformly higher for those two sets (namely quality and income-education) for Rajasthan. In rich states, a similar observation is broadly true for Gujarat with higher magnitudes of elasticities for many of them (Table A38). In urban areas, a comparison of two poor states depicts most of the magnitudes for elasticities to be higher for Rajasthan than MP (Table A38). In rich states, for urban areas, elasticity coefficients have in general higher magnitudes for Maharashtra relative to Gujarat (Table A38). Among the three sets of elasticities, the coefficients are lowest in the magnitudes for all variables pertaining to utilization of any type of care (Table A39). In general, rural elasticities are lower relative to urban counterparts (Table A39). In poor states, across rural areas, MP has generally higher magnitudes (Table A39). In rich states, it is a mixed pattern across Gujarat and
Maharashtra in rural areas (Table A39). In urban areas, with a mixed pattern for quality variables, the income elasticity is higher for MP (Table A39). In rich states' urban areas, there is a mixed pattern for quality variables: the income elasticity is higher for Gujarat and female education elasticity is higher for Maharashtra (Table A39).

\section{Comparison with other studies}

Our high income elasticity coefficients pertaining to public healthcare utilization are in general (except for urban poor states) in line with the results of other Indian studies ${ }^{27}$ and developing countries like Ghana. ${ }^{28}$ Many other studies conducted in countries like Kenya, ${ }^{29}$ Indonesia, ${ }^{30}$ Pakistan, ${ }^{31}$ China, ${ }^{32}$ and Ivory Coast, ${ }^{29}$ have not reported income or quality elasticities.

\section{Conclusions}

Results of the rural all-India level indicate that all the variables are significant. Among the explanatory variables, broadly quality variables indicate that utilization of governmental facilities is hampered by distance, inconvenient timing of facility, absence of health personnel, and poor quality of care as perceived by respondents. The marginal impact of these variables is however small. The elasticity of these variables is particularly high in determining the utilization of governmental facilities. In contrast to governmental facility utilization, the private healthcare facility utilization has positive but low elasticity with respect to quality variables in rural areas. Poverty hampers the utilization of private provider in the rural results. This is denoted by negative impact of BPL card holding.

Most importantly, these results prove healthcare to be a necessity with low elasticities with respect to income and other socioeconomic variables. Nevertheless, choice of a better provider (governmental $v s$ private or no facility $v s$ any facility) is seen through the high responsiveness of rural respondents.

A major difference between rural and urban results is in terms of impact of BPL status. In urban areas, BPL status has been a negative factor in utilizing any type of healthcare facility. There is no notable difference between rural-urban results in terms of water-sanitation impact which shows mixed results. In general, for all the three types of dependent variables, magnitude of income elasticity has been higher in urban areas relative to the rural counterparts, but the difference in magnitude is also low.

In the case of individual state level results, among rich states, the results for Gujarat indicate that high negative elasticity with respect to quality variables and this is impinging on the utilization of public healthcare facilities. It indicates that respondents in urban Gujarat had most important criteria as income and quality to utilize public healthcare. In line with other rich state, namely Gujarat, the results of urban Maharashtra also indicate high elasticity coefficients both with respect to quality and income variable in deciding the utilization of public health facilities. In line with the allIndia rural results, the rural results for Karnataka state representing an average income state also depict high elasticity with respect to quality and income variables only for public healthcare utilization.

Among poor states, results for rural MP depict overall significance of only few variables particularly in regard to utilization of public health facilities. The variables which emerged statistically significant include insurance coverage, type of sanitation and electricity. The impact of these variables and elasticities are low and generally depict a lack of all these, namely insurance coverage (negative sign), sanitation (positive sign) and electricity (positive sign). The results of rural MP for private care utilization depict statistically significant coefficients for most of the variables except water and sanitation. However, elasticity coefficients are very low for all of them, thus again depicting healthcare as a necessity. In contrast to rural results, urban MP results depict high impact and elasticity coefficients for most of the quality variables except absence of health personnel. Unlike the results of urban MP, the results for public care utilization for other poor states, namely Rajasthan for urban areas, do not indicate high elasticity coefficients pertaining to any variables except for poor quality (-1.18) and wealth index (1.49).

Overall our results provide evidence that healthcare demand both in rural and urban areas is a commodity which emerges as an essential need. Choices between public or private provider are guided by income and quality variables mainly in regard to public healthcare, thus denoting a situation of very limited alternatives in terms of availing private providers. These results emphasize that existing public healthcare facilities are not serving the avowed objective of providing care to the poor in a satisfactory manner even in rural areas. Thus, any financing strategy to improve health system and reduce disparities across rich-poor states and rural-urban areas should take into account not only overcoming inadequacy but also inefficiency in allocation and utilization of healthcare inputs. ${ }^{33}$

\section{References}

1. National Health Policy 2002 (India). New 
Delhi: Government of India Publ.; 2003. Available from: www.mohfw.nic.in/NRHM/ ...National_Health_policy_2002.pdf

2. Grossman M. On the concept of health capital and the demand for health. J Polit Econ 1972;80:223-55.

3. Becker GS. Human capital. New York, NY: Columbia University Press; 1964.

4. Becker GS. Human capital and the personal distribution of income: an analytical approach. Ann Arbor, MI: University of Michigan Publ.; 1967.

5. Ben-Porath Y. The production of human capital and the life cycle of earnings. J Polit Econ 1967;75:353-67.

6. Mincer J. Schooling, experience, and earnings. New York, NY: Columbia University Press; 1974.

7. Becker GS. A theory of the allocation of time. Econ J 1965;75:493-517.

8. Lancaster KJ. A new approach to consumer theory. J Polit Econ 1966;74:132-57.

9. Michael RT. Education in non-market production. J Polit Econ 1973;81:306-27.

10. Rosenzweig MR, Schultz TP. Estimating a household production function: heterogeneity, the demand for health inputs and their effects on birth weight. J Polit Econ 1983;91:723-46.

11. Schultz TP. Studying the impact of household economic and community variables on child mortality. Popul Dev Rev 1984;10:S25-45.

12. Behrman JR, Deolalikar AB. Health and nutrition. In: Chenery H, Srinivasan TN, eds. Handbook of development economics. Amsterdam: North Holland Press; 1988. pp 631-771.

13. Strauss J, Thomas D. Health, nutrition and economic development. J Econ Lit 1998;36: 766-817.

14. Mosley WH, Chen LC. An analytical framework for the study of child survival in developing countries. Popul Dev Rev 1984;10: S25-45.
15. Acton JP. Demand for healthcare among the urban poor, with special emphasis on the role of time. Washington, DC: The Rand Corporation ed.; 1973.

16. Purohit BC. Budgetary expenditure on health and human development in India. Int J Popul Stud 2012;2012: ID 914808.

17. World Health Organization. Meeting the millennium development goals drinking water and sanitation targets: a mid-term assessment of progress. Geneva: WHO ed.; 2004.

18. Flores W. Governance and health in an urban setting: key factors and challenges for latin american cities. In: Tulchin JS, Varat DH, and Ruble BA, eds. Democratic governance and urban sustainability. Washington, DC: Woodrow Wilson International Center for Scholars Publ.; 2000. pp 89-96.

19. Ricardo B, Giedion U, Valenzuela R, Monkkonen P. [La problemática de salud de las poblaciones urbanas pobres en América Latina]. [Book in Spanish]. Washington, DC: World Bank Publ.; 2003.

20. Gouveia N, Fletcher T. Respiratory diseases in children and outdoor air pollution in São Paulo, Brazil: a time series analysis. Occup Environ Med 2000;57:477-83.

21. Pritchett L, Summers L. Healthier is wealthier. Journal of Human Resources 1996; 31:841-68.

22. Kantharia SL. Urban health issues in india - need of the day. Natl J Comm Med. 2010;1:1.

23. Government of India. National commission on macroeconomics and health ministry of health and family welfare. New Delhi: Government of India Publ.; 2005.

24. World Health Organization. The role of health centres in the development of urban health systems, report of the WHO study group on primary healthcare in urban areas. Geneva: WHO ed.; 1992.

25. Planning Commission of India. High level expert group report on universal health coverage for India. New Delhi: Planning Commission of India Publ.; 2011. Available from: http://planningcommission.nic.in/ reports/genrep/rep_uhc0812.pdf

26. International Institute for Population Sciences. National Family Health Survey (NFHS-3), India, 2005-06: state level reports. Mumbai: IIPS ed.; 2008.

27. Duraisamy P. Health status and curative healthcare in rural India. New Delhi: National Council of Applied Economic Research Publ.; 2001.

28. Gaddah M. Progressivity of healthcare services and poverty in Ghana. Tokyo: National Graduate Institute for Policy Studies ed.; 2011.

29. Gertler P, Hammer J. Strategies for pricing publicly provided health services. Washington, DC: World Bank Publ.; 1997.

30. Gertler P, Molyneaux J. Experimental evidence on the effect of raising user fees for publicly delivered healthcare services: utilization health outcomes, and private provider response. Washington, DC: The Rand Corporation ed.; 1997.

31. Alderman H, Gertler P. Family resources and gender differences in human capital investments: the demand for children's medical care in Pakistan. In: Haddad L, Hoddinott J, Alderman H, eds. Intrahousehold resource allocation in developing countries: models, methods, and policy. Baltimore: Johns Hopkins University Press for the International Food Policy Research Institute ed.; 1997.

32. Qian D, Pong RW, Yin A, et al. Determinants of healthcare demand in poor, rural China: the case of Gansu province. Health Policy Plann 2009;24:324-34.

33. Purohit BC. Healthcare system in India. New Delhi: Gayatri Publ.; 2010. 